\title{
Estádios de brotação de gemas de fruteiras de clima temperado para o teste biológico de avaliação de dormência
}

\author{
Budburst stages of temperate zone fruit to the \\ biological test ofdormancy evaluation
}

\author{
Ruy Inácio Neiva de Carvalho ${ }^{[a]}$, Luiz Antônio Biasi ${ }^{[b]}$, \\ Flávio Zanette ${ }^{[c]}$, Jean Magnus Santos ${ }^{[\mathrm{d}]}$, Gabriely Pinto Pereira ${ }^{[\mathrm{e}]}$
}

[a] Engenheiro agrônomo, Doutor, professor titular do Centro de Ciências Agrárias e Ambientais da Pontifícia Universidade Católica do Paraná, (PUCPR), São José dos Pinhais, PR - Brasil, e-mail: ruy.carvalho@pucpr.br

${ }^{[b]}$ Engenheiro agrônomo, Doutor, Departamento de Fitotecnia e Fitossanitarismo da Universidade Federal do Paraná (UFPR), bolsista de Produtividade em Pesquisa do CNPq, Curitiba, PR - Brasil, e-mail: biasi@ufpr.br; flazan@ufpr.br

[c] Engenheiro agrônomo, professor titular sênior da Universidade Federal do Paraná (UFPR), Departamento de Fitotecnia e Fitossanitarismo, bolsista de Produtividade em Pesquisa do CNPq, Curitiba, PR - Brasil, e-mail: biasi@ufpr.br

[d] Engenhiro agrônomo, Curitiba, PR - Brasil, e-mail: jmferoldi@yahoo.com.br

${ }^{[e]}$ Estudante de Agronomia da Pontifícia Universidade Católica do Paraná (PUCPR), bolsista PIBIC, Curitiba, PR - Brasil, e-mail: gabyp.pereira@hotmail.com

\section{Resumo}

O objetivo deste trabalho foi padronizar os estádios de brotação de gemas de ameixeira, caquizeiro, macieira, pereira, pessegueiro, kiwizeiro e videira para o teste biológico de avaliação de dormência. O experimento foi realizado no outono e inverno de 2008. O teste biológico foi conduzido com 40 estacas com $6 \mathrm{~cm}$ de comprimento para cada espécie, contendo apenas uma gema lateral na porção superior. As gemas recém coletadas e acondicionadas nas câmaras de crescimento, à temperatura de $25^{\circ} \mathrm{C} \mathrm{e}$ fotoperíodo de $16 \mathrm{~h}$, foram fotografadas e consideradas gemas dormentes. A análise visual das estacas foi realizada a cada dois dias, até a detecção dos estádios de brotação ponta verde (PV) e gema aberta (GAb). O número de dias necessário para atingir o estádio PV e o tempo para detecção do estádio $\mathrm{GAb}$ foram determinados. As formas mais representativas de brotação das gemas foram fotografadas e as peculiaridades foram observadas para caracterização dos estádios. Gemas de ameixeira, macieira e pessegueiro apresentam o estádio de brotação PV bem evidenciado, ficando com o ápice esverdeado. Gemas de caquizeiro e pereira têm o estádio PV iniciado pelo esverdeamento da base da gema, sendo comum na pereira a necrose do ápice dos catáfilos e primórdios foliares. Os estádios PV de gemas de quivizeiro e videira se caracterizam pelo aparecimento de tecidos amarelados. O estádio de brotação GAb é facilmente identificado pela expansão do limbo foliar da primeira folha exteriorizada da gema para todas as espécies.

Palavras-chave: Fisiologia vegetal. Endodormência. Crescimento. 


\section{Abstract}

The objective of this work was to standardize the budburst stages of plum, persimmon, apple, pear, peach, kiwi and grape trees for the biological test of dormancy evaluation. The experiment was carried through in the autumn and winter of 2008. The biological test was conducted with 40 cuttings of 6 $\mathrm{cm}$ in length for each species, with only one lateral bud in the upper portion. The buds were collected and conditioned in the growth chambers (temperature of $25^{\circ} \mathrm{C}$ and photoperiod of 16 hours) and had been photographed and considered dormant buds. Visual analysis of the cuttings was carried through until the observation of budburst green tip (GT) stage and open leaves (OL) stage. The number of days necessary to reach the GT stage and the time for detention of the OL stage had been determined. The forms most representative of budburst had been photographed and the peculiarities had been observed. Buds of plum, apple and peach trees present the GT stage well evidenced, being the same ones with the greening apex. Persimmon and pear tree buds have the GT stage initiated for the greening of the bud base, being common in the pear tree buds the necrosis of the apex of the scales and primordial leaves. GT stage of kiwi and grape buds was characterized for the appearance of yellow tissue. The OL stage was easily identified by the expansion of the foliar limb of the first leaf of the bud for all the species.

Keywords: Plant physiology. Endodormancy. Growth.

\section{Introdução}

Os aspectos envolvidos na entrada, manutenção e liberação da dormência de gemas de espécies frutíferas ainda não são totalmente conhecidos. O crescimento ou não de uma gema é uma resposta à combinação de fatores relativos ao ambiente (ecodormência), à influência de outro órgão do vegetal (paradormência) ou a eventos bioquímicos e fisiológicos que acontecem no interior da gema (endodormência) (LANG et al., 1987). Desde a década de 1990, as espécies de clima temperado como a macieira (PUTTI et al., 2003), o caquizeiro (MOWAT et al., 1995; FAQUIM et al., 2007), a pereira (GIL; LYON, 1994; OLIVEIRA et al., 2008) e o pessegueiro (BALANDIER et al., 1992; OLIVEIRA FILHO; CARVALHO, 2003) têm sido estudadas.

Um método para avaliação rápida da endodormência de gemas já foi objetivo de muitas pesquisas. Dentre os métodos mais conhecidos e aplicados destacam-se três grupos: os testes empíricos, bioquímicos e biológicos.

Os métodos empíricos baseiam-se em modelos matemáticos de quantificação do acúmulo de horas de frio (HF) ou unidades de frio (UF) para atender às exigências de uma cultivar. Quando há acúmulo de um número específico de HF ou UF exigido pela planta, considera-se que a endodormência já foi eliminada e as gemas teriam potencial para brotação. Para regiões com inverno ameno e espécies com baixa exigência em frio foi determinado o modelo de Utah (RICHARDSON et al., 1974), e para regiões com inverno mais rigoroso foi proposto o modelo de Carolina do Norte (SHALTOUT; UNRATH, 1983). Algumas modificações desses modelos foram realizadas posteriormente com o objetivo de reduzir o efeito anulador do somatório de unidades de frio com valor negativo (PETRI et al., 1996; POLA et al., 1994).

Os testes bioquímicos foram desenvolvidos com base na capacidade de síntese de adenosina trifosfato (ATP) e nucleotídeos não adenínicos (NTP) por gemas vegetativas. As avaliações são feitas em primórdios contidos nas gemas após sua incubação em meio com e sem adenosina, precursor destes nucleotídeos. O aumento do nível de NTP e de ATP revela a capacidade de síntese da gema e a ausência de endodormência, sem considerar as condições ambientais preliminares (BONHOMME et al., 2000).

Alguns estudos bioquímicos para avaliação da endodormência concentram-se na variação do conteúdo de proteínas nas gemas (TAMURA etal., 1998), do conteúdo de ácidos gordurosos nos fosfolipídeos das membranas celulares das gemas (EREZ, 2000), da quantidade e atividade da ATPase na membrana 
plasmática das gemas e tecidos adjacentes (AUE et al., 1998, 2000), da intensidade de respiração das gemas durante o outono e inverno (McPHERSON et al., 1997) e da dinâmica de carboidratos (CARVALHO; ZANETTE, 2005).

O teste biológico de avaliação da dormência, conhecido como “estacas de nós isolados”, fundamentase no tempo necessário para a brotação de gemas isoladas em fragmentos do ramo e submetidas à temperatura de $20^{\circ} \mathrm{C}$ a $25^{\circ} \mathrm{C}$ e dias longos. A avaliação da dinâmica da dormência é feita por meio da análise da evolução do tempo necessário para brotação de um grupo de gemas num determinado período (MAUGET, 1987).

O teste biológico é considerado como o único capaz de quantificar a dormência de gemas, sendo capaz de identificar as variações temporal, espacial e genética (HERTER et al., 2001). No Brasil, esse método é aplicado nas principais espécies frutíferas de clima temperado, dentre elas a macieira (CARVALHO; ZANET'TE, 2004b) e a pereira (BIANCHI et al., 2000). Porém, os resultados não coincidem com os verificados por métodos empíricos baseados no acúmulo de unidades de frio e de calor (HERTER et al., 1992).

Um fator limitante à aplicação precisa do teste biológico é a detecção do momento exato para se determinar o início e o fim da brotação da gema. Com base nestes dois estádios de brotação são feitos os cálculos dos parâmetros de tempo médio para brotação (TMB), taxa final de brotação (TF), taxa de brotações vigorosas (TBV) e velocidade de brotação (VB). Assim, a comparação visual das gemas com um modelo padronizado será uma importante ferramenta para a homogeneização dos resultados obtidos nesses testes em laboratório.

O objetivo deste trabalho foi padronizar os estádios de brotação de gemas de ameixeira, caquizeiro, macieira, pereira, pessegueiro, kiwizeiro e videira para o teste biológico de avaliação de dormência.

\section{Materiais e métodos}

O experimento foi realizado no outono e inverno de 2008. Os ramos de macieira cv. Imperial Gala e pereira cv. Hosui foram coletados na Fazenda Perboni, no município de Porto Amazonas, PR, e os ramos de pessegueiro cv. Chimarrita e de ameixeira cv Poli, na Fazenda Experimental Gralha Azul, da Pontifícia Universidade Católica do Paraná (PUCPR), no município de Fazenda Rio Grande, PR. Os ramos de videira cv. Niagara Branca e de kiwizeiro cv Bruno foram coletados nos pomares da Estação Experimental do Canguiri, da Universidade Federal do Paraná (UFPR), no município de Pinhais, PR. Para as sete espécies estudadas, foram coletados apenas ramos mistos de um ano, íntegros, sadios e com gemas bem formadas.

Os testes biológicos foram conduzidos com gemas de ameixeira, caquizeiro, macieira, pereira e pessegueiro, no Laboratório de Técnica de Sementes da PUCPR, câmpus São José dos Pinhais, em câmaras climatizadas BOD. Os testes com as gemas de kiwizeiro e videira foram realizados em sala de crescimento no Departamento de Fitotecnia da UFPR. Em ambos os casos, as condições ambientais foram temperatura de $25^{\circ} \mathrm{C}$ e fotoperíodo de $16 \mathrm{~h}$.

Foram confeccionadas 40 estacas com $6 \mathrm{~cm}$ de comprimento para cada espécie, contendo apenas uma gema lateral na porção superior. $\mathrm{Na}$ videira foram utilizadas as gemas situadas entre o segundo e o décimo nó, contados a partir da base dos ramos, e no kiwizeiro foram utilizadas as gemas situadas entre o quarto e o décimo quarto nó. Para as demais espécies foi utilizada a porção mediana dos ramos coletados. Para a ameixeira e o pessegueiro foram utilizadas estacas com um grupo de três gemas formado por uma gema vegetativa central e duas gemas floríferas laterais.

Uma amostra de ramos foi acondicionada em geladeira à temperatura de $4^{\circ} \mathrm{C}$ a $7^{\circ} \mathrm{C}$, por um período de $504 \mathrm{~h}$ para o pessegueiro, ameixeira e caquizeiro, e de $1.440 \mathrm{~h}$ para a macieira, pereira, kiwizeiro e videira, em substrato de vermiculita umedecida.

As gemas recém coletadas e acondicionadas nas câmaras de crescimento foram fotografadas e consideradas gemas dormentes. A análise visual das estacas foi realizada a cada dois dias, até a detecção dos estádios de brotação ponta verde (PV) e gema aberta (GAb). O número de dias necessário para atingir o estádio PV e o tempo para detecção do estádio GAb foram determinados. As formas mais representativas de brotação das gemas foram fotografadas e as peculiaridades foram observadas para caracterização dos estádios. 


\section{Resultados}

Pela análise visual das gemas endodormentes da ameixeira evidenciou-se que a gema central vegetativa é maior do que as gemas floríferas laterais no período de endodormência. $O$ estádio de brotação ponta verde, que indica o início da brotação, foi determinado quando a gema apresentou-se alongada, os catáfilos começaram a se separar e apareceu no ápice da gema a porção apical das primeiras folhas. Estas primeiras folhas alongam-se e, em cerca de seis dias, detecta-se o estádio de brotação gema aberta, caracterizado pela expansão do limbo foliar de uma ou mais folhas ao mesmo tempo (Figura 1).

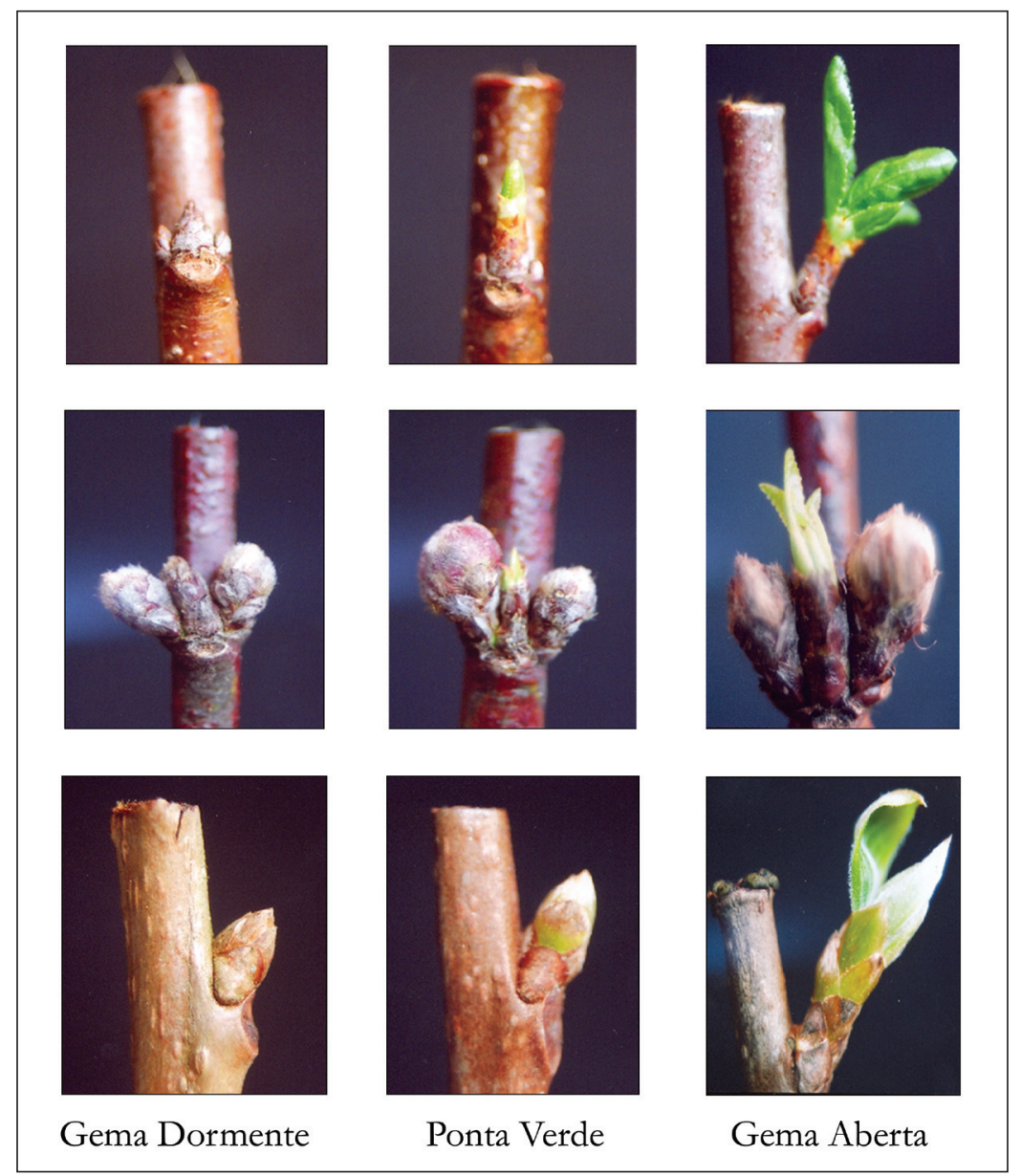

Figura 1 - Estádios de brotação de gemas de ameixeira, pessegueiro e caquizeiro para avaliação do teste biológico de dormência

Para as gemas endodormentes de ameixeira, o estádio de brotação PV ocorre de 11 a 25 dias após a instalação do teste e, com o suprimento de frio necessário para superação da endodormência, o estádio PV é detectado já do terceiro ao quinto dia.

Os grupos selecionados de gemas dormentes de pessegueiro são formados por uma gema vegetativa central ladeada por duas gemas floríferas de dimensões iguais ou superiores a ela. O estádio PV é detectado pela separação da porção apical dos catáfilos por onde surgem as primeiras folhas facilmente visíveis. Após cerca de três dias detecta-se o estádio GAb, determinado pelo alongamento e expansão de uma ou mais folhas. Segundo Oliveira Filho e Carvalho (2003), gemas de pessegueiro demoraram de 1,8 a 5,9 dias para passar do estádio PV ao GAb. A visualização de ao menos parte do limbo foliar expandido é necessária, pois muitas gemas endodormentes alongam-se muito para o exterior dos catáfilos sem que a folha se desenrole, permanecendo com o crescimento paralisado (Figura 1). 
Para as gemas endodormentes de pessegueiro, o estádio de brotação PV ocorre de 16 a 23 dias após a instalação do teste e, com o suprimento de frio necessário para superação da endodormência, o estádio PV é detectado já no segundo dia. De acordo com Oliveira Filho e Carvalho (2003), o tempo médio para aparecimento do estádio PV em gemas de pessegueiro Eldorado e Ágata é de 25 a 30 dias no período de endodormência mais intensa e de 10 dias após a saída da endodormência sem tratamento com frio.

As gemas de caquizeiro endodormentes apresentam-se isoladas e com catáfilos de consistência firme, porém os mais externos envolvem apenas a base da gema. De forma diferenciada das demais espécies, os catáfilos mais externos praticamente não se alteram no início de crescimento da brotação da gema, e os catáfilos mais internos alongam-se e apresentam sua base esverdeada, detectando-se, assim, o estádio de brotação PV. Cerca de sete dias após o estádio PV os catáfilos mais internos tornam-se totalmente verdes e afastam-se, permitindo a emissão das primeiras folhas, que surgem já parcialmente expandidas com uma porção do limbo foliar à mostra, caracterizando o estádio GAb (Figura 1). Segundo Carvalho e Alves (2007), o tempo necessário para passagem do estádio PV ao GAb de gemas de caquizeiro Fuyu é de 8 a 12,2 dias.

Para as gemas endodormentes de caquizeiro, o estádio de brotação PV ocorre de 21 a 37 dias após a instalação do teste e, com o suprimento e frio necessários para superação da endodormência, o estádio PV é detectado do $5^{\circ}$ ao $26^{\circ}$ dia. Faquim et al. (2007) verificaram que gemas de caquizeiro Fuyu, na endodormência mais intensa, levaram de 28 a 30,7 dias para atingir o estádio PV e, após tratamento com frio adicional, o tempo foi reduzido para o intervalo de 14,2 a 15,6 dias. Carvalho e Alves (2007) encontraram tempo médio de 31 dias para surgimento da PV no período de endodormência mais intensa, e de 22 dias após a saída natural da endodormência, sem tratamento com frio adicional.

As gemas de pereira são as que possuem brotação mais desuniforme, o que dificulta a execução e avaliação do teste biológico. Mesmo as gemas dormentes possuem formas e consistências diferenciadas, de maneira que a seleção de gemas para montagem do teste é fundamental. Assim mesmo, alguns distúrbios fisiológicos só surgem após o início da brotação, como o abortamento de gemas, que já se inicia antes do inverno (ARRUDA; CAMELATTO, 1999). Esses fatos evidenciam que a detecção do estádio PV em gemas de pereira pode ocorrer tanto pelo ápice quanto pela base da gema, sendo esta última a forma mais comum. O afastamento dos catáfilos ocorre de forma discreta e a primeira folha surge, muitas vezes, já com seu ápice necrosado. Ao mesmo tempo, a base dos catáfilos torna-se esverdeada e estes se separam de foram mais evidente, por onde se alongam as folhas sem necrose. Após cerca de nove dias as folhas se abrem de forma muito visível, deixando à mostra o limbo foliar, caracterizando o estádio GAb (Figura 2).

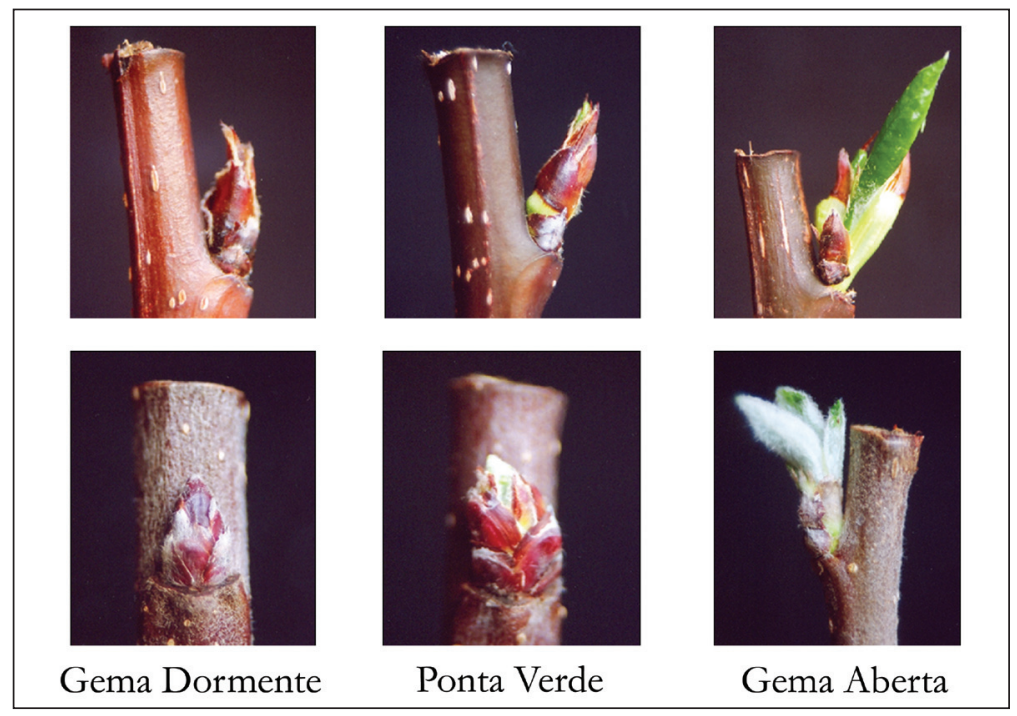

Figura 2 - Estádios de brotação de gemas de pereira e macieira para avaliação do teste biológico de dormência

Para as gemas endodormentes de pereira, o estádio de brotação PV ocorre de 14 a 38 dias após a instalação do teste e, com o suprimento de frio necessário para superação da endodormência, o estádio PV 
é detectado já do terceiro ao décimo dia. De acordo com Bianchi et al. (2000), o surgimento do estádio PV em gemas de pereiras asiáticas Hosui e Século XX ocorreu após 22 dias na entrada da endodormência, e em gemas de pereiras europeias Barttlet e Packham's Triumph ocorreu após 13 dias, na mesma época.

As gemas de macieira encontram-se isoladamente em cada nó e também apresentam diversidade de forma e tamanho, devendo ser feita uma seleção de gemas para execução do teste. O estádio PV é facilmente detectado pela separação do ápice dos catáfilos e aparecimento do ápice verde-prateado das primeiras folhas. Estas se alongam e, após cerca de oito dias abrem-se, permitindo a visualização do limbo foliar (Figura 2).

Para as gemas endodormentes de macieira, o estádio de brotação PV ocorre de 14 a 34 dias após a instalação do teste e, com o suprimento de frio necessário para superação da endodormência, o estádio PV é detectado já do $5^{\circ}$ ao $17^{\circ}$ dia. De acordo com Carvalho e Zanette (2004b), foram necessários 27 dias para o aparecimento do estádio PV em gemas de macieira Imperial Gala na endodormência mais intensa, e sete dias após o tratamento com frio. O estádio GAb foi atingido após 2,5 a 7 dias em gemas que não receberam frio, e após 2,6 a 4,7 dias, quando foi realizado o tratamento com frio. Carvalho e Zanette (2004a) determinaram que o estádio de brotação PV em gemas de dois anos de macieira Imperial Gala ocorreu, em média, em 25 dias na endodormência mais profunda e em 10 dias após o tratamento com frio, e o estádio GAb foi detectado após cerca de 2,4 a 4,2 dias, independentemente do suprimento de frio à gema.

As gemas endodormentes de kiwizeiro não apresentam catáfilos definidos e aparentes e localizamse isoladamente sempre acima de uma evidente cicatriz deixada pela abscisão da folha na estação anterior. O estádio PV é definido pelo rompimento dos tecidos dessa região acima da cicatriz foliar e pelo aparecimento dos primórdios foliares, com muitos pelos de coloração amarelada ou alaranjada. Esses se alongam e, após por volta de 9,6 dias sem suprimento de frio ou de 4,7 dias com suprimento de frio, abrem-se, permitindo a visualização do limbo foliar (Figura 3). Com frequência observou-se a formação de calos nas extremidades das estacas, originados do meristema secundário e formando um círculo de coloração verde no corte superior e branca no corte inferior. Essa ocorrência de calos não foi prenúncio de brotação e ocorreu mesmo em estacas com gemas endodormentes.

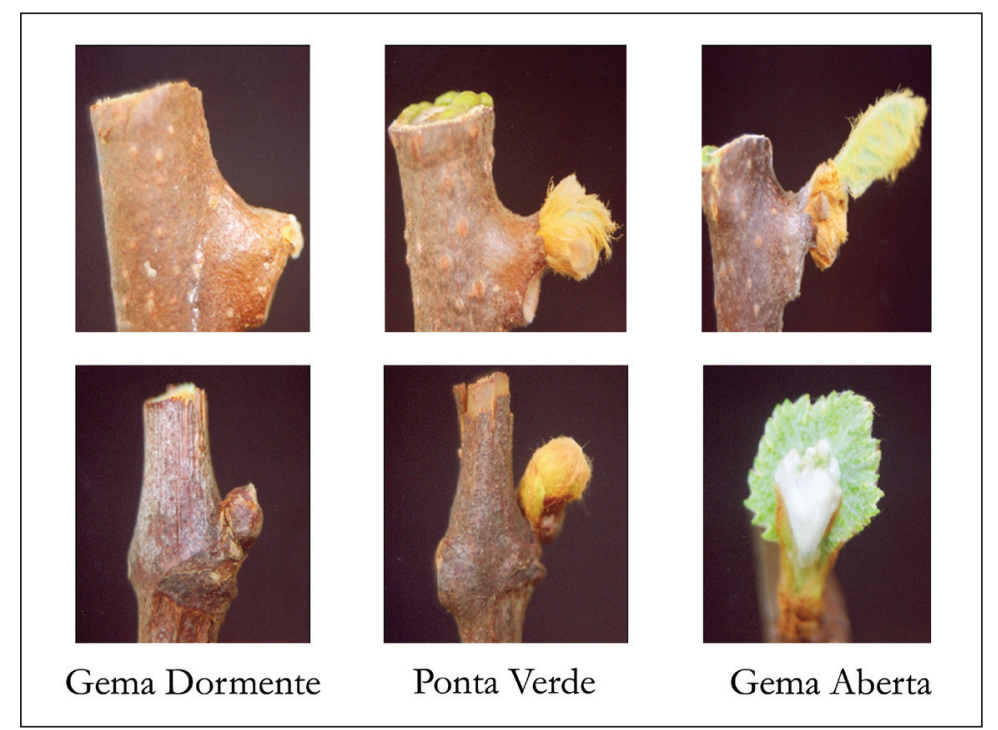

Figura 3 - Estádios de brotação de gemas de quivizeiro e videira para avaliação do teste biológico de dormência

Para as gemas endodormentes de kiwizeiro, o estádio de brotação PV ocorre de 42 a 61 dias após a instalação do teste e, com o suprimento de frio necessário para superação da endodormência, o estádio PV é detectado já do $5^{\circ}$ ao $12^{\circ}$ dia.

As gemas endodormentes de videira localizam-se de forma isolada em cada nó do bacelo. $\mathrm{O}$ estádio PV é detectado quando os catáfilos se separam e surgem os primórdios foliares ainda enrolados e com pelos de coloração amarela ou alaranjada. Por volta de 5,6 dias depois, uma folha se expande, deixando visível seu limbo foliar (Figura 3). 
Para as gemas endodormentes de videira, o estádio de brotação PV ocorre de 15 a 44 dias após a instalação do teste e, com o suprimento de frio necessário para superação da endodormência, o estádio PV é detectado já do segundo ao quinto dia.

Para todas as espécies analisadas, nem todas as gemas que atingem o estádio PV evoluem para o estádio GAb, e a ocorrência deste fato pode evidenciar a endodormência da gema, uma vez que o início da brotação pode ser apenas uma resposta ao corte efetuado para a preparação da estaca. A parada de crescimento indica que a gema não estava fisiologicamente preparada para continuidade da brotação, caracterizando a endodormência.

\section{Conclusões}

- Gemas de ameixeira, macieira e pessegueiro apresentam o estádio de brotação ponta verde bem evidenciado, ficando com o ápice esverdeado;

- Gemas de caquizeiro e pereira têm o estádio ponta verde iniciado pelo esverdeamento da base da gema, sendo comum na pereira a necrose do ápice dos catáfilos e primórdios foliares;

- O estádio ponta verde de gemas de kiwizeiro e videira se caracteriza pelo aparecimento de tecidos amarelados e com muitos pêlos;

- O estádio de brotação gema aberta é facilmente identificado pela expansão do limbo foliar da primeira folha exteriorizada da gema, para todas as espécies.

\section{Referências}

ARRUDA, J. J. P.; CAMELATTO, D. Abortamento de gemas florais de cinco cultivares de pereira (Pyrus spp., L.) em dois locais do Rio Grande do Sul, BRASIL. Ciência Rural, v. 29, n. 4, p. 635-638, 1999.

AUE, H. L. et al. Activity and quantitative analysis of plasmalemma ATPase in buds and bud stands during winter vegetative bud's dormancy in peach-tree. Acta Horticulturae, n. 465, p. 531-538, 1998. Disponível em: <http://www.actahort.org/books/465/465_66.htm>. Acessado em: 20, set. 2009.

. et al. Changes in the parameters of the plasmalemma ATPase during peach vegetative bud dormancy. Biologia Plantarum, v. 43, n. 1, p. 25-29, 2000.

BALANDIER, P. et al. Étude de la croissance et du dévelopement des bourgeons du pêcher cultivé à l'île de la Réunion: application a l'élaboration d'une itinéraire cultural. Fruits, v. 47, n. 6, p. 679-689, 1992.

BIANCHI, V. J. et al. Estudo da paradormência em pereira por meio do método biológico. Revista Brasileira de Fruticultura, v. 22, n. 2, p. 294-296, 2000.

BONHOMME, M. et al. ATP, ADP and NTP contents in vegetative and floral peach buds during winter: are they useful for characterizing the type of dormancy? In: VIÉMONT, J.-D.; CRABBÉ, J. (Ed.). Dormancy in plants: from whole plant behavior to cellular control. Cambridge, MA:University Press, 2000. p. 245-257.

CARVALHO, R. I. N. de; ALVES, M. C. A. Intensidade de dormência das gemas de caquizeiro 'Fuyu’ no período do outono e inverno na região de Fazenda Rio Grande - PR. Revista Brasileira de Agrociência, v. 13, n. 1, p. 35-38, 2007.

CARVALHO, R. I. N. de; ZANET'TE, F. Dinâmica da dormência de gemas de dois anos de macieira 'Imperial Gala’ em região de baixa ocorrência de frio. Revista Brasileira de Fruticultura, v. 26, n. 3, p. 392-394, 2004 a.

- Dinâmica da dormência de gemas de macieira 'Imperial Gala' durante o outono e inverno em região de baixa ocorrência de frio. Revista Brasileira de Fruticultura, v. 26, n. 1, p. 65-68, 2004b.

- Variações do conteúdo de carboidratos em gemas e ramos de dois anos de macieira em região de baixa ocorrência de frio. Revista Brasileira de Fruticultura, v. 27, n. 3, p. 352-355, 2005. 
EREZ, A. Bud dormancy: a suggestion for the control mechanism and its evolution. In: VIÉMONT, J. D.; CRABBÉ, J. (Ed.). Dormancy in plants: From whole plant behavior to cellular control. Cambridge, MA: University Press, 2000. p. 23-33.

FAQUIM, R. et al. Necessidade de frio para quebra de dormência de gemas de caquizeiro 'Fuyu'. Revista Brasileira de Fruticultura, v. 29, n. 3, p. 438-444, 2007.

GIL, G. F.; LYON, M. Dormancy of 'Packam's Triumph' and 'Winter Nelis' pear buds in relation with chilling, hydrogen cyanamide and thiourea. Acta Horticulturae, n. 367, p. 248-254, 1994. Disponível em: <http:// www.actahort.org/books/465/465_66.htm>. Acesso em: 20 Set. 2009.

HERTER, F. G. et al. Determinação do término da dormência e floração para algumas cultivares de macieira: comparação entre métodos biológico e empírico. Revista Brasileira de Fruticultura, v. 14, n. 1, p. 77-81, 1992.

HERTER, F. G. et al. Níveis de carboidratos em tecidos de pereira cv Nijisseiki em duas épocas que antecedem o florescimento. In: CONGRESSO BRASILEIRO DE FISIOLOGIA VEGETAL, 8., 2001, Ilhéus. Anais... Ilhéus: SBF, 2001. CD-ROM.

LANG, G. A. et al. Endo-, para- and ecodormancy: physiological terminology and classification for dormancy research. HortScience, v. 22, n. 3, p. 371-378, 1987.

MAUGET, J. C. Dormance des bourgeons chez les arbres fruitiers de climat tempéré. In: GUYADER, H. Le développement des végétaux: aspects théoriques et synthétiques. 1987. p. 133-150.

McPHERSON, H. G. et al. Bud respiration and dormancy of kiwifruit (Actinidia deliciosa). Annals of Botany, v. 80, n. 4, p. 411-418, 1997.

MOWAT, A. D. et al. The effect of root temperature on bud dormancy release of persimmon (Diospyros kaki L.). Acta Horticulturae, v. 1, n. 409, p. 137-140, 1995.

OLIVEIRA, O. R. et al. Quebra de dormência de pereira 'Hosui' com uso de óleo mineral em dois tipos de condução. Revista Brasileira de Fruticultura, v. 30, n. 2, p. 409-413, 2008.

OLIVEIRA FILHO, P. R. C.; CARVALHO, R. I. N. Dinâmica da dormência em gemas de pessegueiro das variedades Eldorado e Ágata. Revista Acadêmica: Ciências Agrárias e Ambientais, v. 1, n. 3, p. 41-46, 2003.

PETRI, J. L. et al. Dormência e indução da brotação de fruteiras de clima temperado. Florianópolis: Epagri, 1996. (Boletim Técnico, 75).

POLA, A. C. et al. Avaliação de modelos de unidades e horas de frio para a previsão do início de brotação em macieira, cv Gala. Revista Brasileira de Fruticultura, v. 16, n. 1, p. 105-118, 1994.

PUTTI, G. L. et al. Temperaturas efetivas para a dormência da macieira (Malus domestica Borkh.). Revista Brasileira de Fruticultura, v. 25, n. 2, p. 210-212, 2003.

RICHARDSON, E. A. et al. A model for estimating the completion of rest for 'Redhaven' and 'Elbert' peach trees. HortScience, v. 9, n. 4, p. 331-332, 1974.

SHALTOUT, A. D.; UNRATH, C. R. Rest completion prediction model for 'Starkrimson Delicious' apples. Journal of the American Society for Horticultural Science, v. 108, n. 6, p. 957-961, 1983.

TAMURA, F. et al. Protein changes in the flower buds of Japanese pear during breaking of dormancy by chilling or high-temperature treatment. Journal of the American Society for Horticultural Science, v. 123 , n. 4 , p. 532-536, 1998.

Recebido: 23/11/2009

Received: $11 / 23 / 2009$

Aprovado: 22/12/2009

Approved: 12/22/2009 